\title{
Performance of Pleurotus pulmonarius mushroom grown on maize stalk residues supplemented with various levels of maize flour and wheat bran
}

\author{
Senzosenkosi Surprise MKHIZE ${ }^{1 *}$, Godfrey Elijah ZHARARE², Albertus Kotze BASSON ${ }^{1}$, \\ Mathews Simon MTHEMBU ${ }^{1}$, Jacques CLOETE ${ }^{3}$
}

\begin{abstract}
The use of supplemented agricultural waste in mushroom cultivation can be one of the environmentally friendly strategies for poverty alleviation. The study evaluated the performance of Pleurotus pulmonarius mushroom grown on maize stalk supplemented with varying levels of wheat bran (WB) and maize flour (MF). A completely random design was used for the experiments. It was observed that Pleurotus pulmonarius was significantly affected by varying levels of supplementation, as $20 \%$ WB supplementation encountered higher contamination. The lower supplementation levels gave significantly shorter colonisation period with better mycelial growth rate (MGR). The $2 \% \mathrm{MF}, 2 \% \mathrm{WB}$ and $4 \% \mathrm{WB}$ gave significantly higher MGR and faster colonisation. The shortest pinning time (TP) was observed at the first flush with the minimum of 2 days. Higher supplementation levels gave maximum yield and biological efficiency (BE). With further increase of supplementation above a $12 \% \mathrm{WB}$ and $14 \% \mathrm{MF}$, the BE and yield declined. Lower supplementation levels resulted in quicker colonisation period and improved growth rate, whereas high supplementation gave better production in terms of yield and BE. Therefore, for the purpose of maximum production, $12 \% \mathrm{WB}$ and $14 \% \mathrm{MF}$ may be recommended while for fast production time, $2 \% \mathrm{MF}$ and $2 \% \mathrm{WB}$ are recommended.
\end{abstract}

Keywords: production; biological efficiency; yield; supplement levels.

Practical Application: Improving production and growth of $P$. pulmonarius using different supplement ratios.

\section{Introduction}

Mushrooms are recognized as fungi with fruiting bodies that decompose their growth media using biochemical processes in order to obtain energy and growth material (Chang, 1991). Previous studies have reported that amongst the known mushroom species, over 2000 species of mushroom are recognized as edible. However, 25 species out of these are considered to be intensively cultivated commercially (Hussein et al., 2015). Among the 25 species of mushroom, oyster mushroom ranks the third world wide (Obodai et al., 2003). The process of mushroom cultivation has lot of advantages such as that, it utilises little land for production, which renders them economically beneficial (Dzomeku, 2009). Mushroom farming is an alternative way of alleviating poverty, because of relatively quick returns and inexpensive production (Masarirambi et al., 2011). Besides these benefits of mushroom farming, oyster mushrooms contains medicinal properties which makes them suitable for treatment and prevention of different diseases (Gunde-Cimerman \& Cimerman, 1995; Pramanik et al., 2005; Alarcón \& Águila, 2006; Jedinak \& Sliva, 2008). For example Pleurotus pulmonarius contain anti-nociceptive, anti-inflammatory and also anti-proliferative actions (Smiderle et al., 2008; Lavi et al., 2010). In common with other Pleurotus species, P. pulmonarius has characteristics that facilitate intensification of its production. For example, it is an aggressive growing fungi with simple cultivation which gives higher yield with good nutritional value (Wahab et al., 2014). Furthermore, this edible and medicinal mushroom is able to break down lignin and other aromatic compounds, since it produces enzymes such as laccase (Lac), manganese oxidizing peroxidase $(\mathrm{Mn}$ - dependent peroxidase $(\mathrm{MnP})$ and versatile peroxidase (VP)) and aryl-alcohol oxidase (AAO) (Munoz et al., 1997). These enzymes allow $P$. pulmonarius to be easily grown on various lignocellulosic materials which include paper materials, sawdust and agricultural wastes material (Croan, 2000). Substrates for mushroom growth may be divided into those regarded as major materials (lignocellulose source) and those regarded as supplementary materials (nitrogen and minerals sources) (Zhang, 2005). Both the major and the supplementary materials are useful in mushroom growth since the substrate composition has a huge impact on the biological efficiency of mushroom (Chang-Ho \& Yee, 1977; Chang \& Miles, 1982) and the addition of supplements results in an increased yield (Royse, 2002). 
Other researchers have emphasised that the ideal substrate for Pleurotus mushroom species production should consist of an adequate source of nitrogen and a lignocellulose substrate that provides enough carbohydrate (Oei, 1996; Ayodele \& Okhuoya, 2007). To determine whether the substrate had enough nitrogen and carbohydrates, the efficiency of the process and the productivity is monitored through the parameter called biological efficiency of the mushroom (Chang et al., 1981).

In Northern part of KwaZulu-Natal (KZN) in the Republic of South Africa (RSA), there is a huge amount of agricultural waste produced by local farms. The local farms produce lot of maize residues which end up polluting the environment since maize residues are usually burnt leading to negative environmental impacts. The current study focuses on converting these waste found within the northern KZN area into value added food in a form of $P$. pulmonarius mushroom production. However there is lack of information on how to convert these local agricultural waste into nutrients for P. pulmonarius mushroom with improved yield, short production time at minimal contamination. It was therefore the objective of this work to evaluate the performance of $P$. pulmonarius mushroom when grown on maize stalk residues which are supplemented with varying levels of both maize flour and wheat bran supplements.

\section{Materials and methods}

\subsection{The collection of substrates and supplements}

Maize stalk residues were collected from local farmers in Northern KwaZulu Natal (KZN), Republic of South Africa (RSA) and were kept at room temperature. The maize flour supplement which was free of vitamins was collected form Empangeni millers in KZN. The wheat bran supplement was collected from a local market in KZN named the Coastal Farmers.

\subsection{The oyster mushroom strain}

P. pulmonarius (M2204) mushroom was received from the company called Mycelia in Belgium. Potato dextrose agar (PDA) (MERCK, 1.10130) was used to pre-culture the P. pulmonarius mushroom and thereafter the mushroom cultures were incubated at room temperature $\left(25^{\circ} \mathrm{C}\right)$. The mushroom cultures were maintained as working spawn cultures at $4{ }^{\circ} \mathrm{C}$ for further use.

\subsection{The oyster mushroom spawn preparation}

The method described by Fritsche (1978) was modified to prepare the mushroom spawn. $1 \mathrm{~kg}$ of white sorghum grains were soaked in 1.5 litres of water overnight. The excess water was drained off from the soaked grains. $900 \mathrm{~g}$ of the soaked grains were mixed with $12 \mathrm{~g}$ of gypsum together with $3 \mathrm{~g}$ of $\mathrm{CaCO}_{3}$ and packed half way into $250 \mathrm{ml}$ Schott bottles. The packed grains within the $250 \mathrm{ml} \mathrm{Schott} \mathrm{bottles} \mathrm{were} \mathrm{then} \mathrm{sterilised} \mathrm{in} \mathrm{an} \mathrm{autoclave}$ (Labtech, LAC5060S) at $121^{\circ} \mathrm{C}(103.4 \mathrm{kPa})$ for 15 minutes and thereafter allowed to cool down to room temperature. After sterilisation the grain mixture were inoculated with $\pm 10 \mathrm{~mm}^{2}$ of a previously prepared pure culture of $P$. pulmonarius mushroom in a laminar flow hood. The inoculated grain mixtures were incubated in a dark room at $25^{\circ} \mathrm{C}$ for 14 days until the grain mixture were fully colonised by the mycelia.

\subsection{The preparation of maize stalk substrate}

The maize stalk substrate was prepared using a modified procedure by Bano \& Srivastava (1962). The dry weight of the milled maize stalk was measured, which assisted in the calculation of other parameters. A measured amount of tap water was added into the maize stalk substrate in order to obtain a standard moisture of $65 \%$. The $65 \%$ moisture was obtained using the method called the rule of thumb whereby 1-2 drops of water were released when the substrate was squeezed into the hand (Kwon, 2004). The substrates were supplemented separately with varying levels of both wheat bran and maize flour supplements, wiz; $0 \%$, $2 \%, 4 \%, 8 \%, 12 \%, 14 \%, 18 \% \& 20 \%$. After a complete substrate supplementation, $1 \mathrm{~kg}$ of the supplemented substrate was packed into polypropylene bags of $22.5 \mathrm{~cm} \times 30 \mathrm{~cm}$. The substrate was manually packed into bags and compressed by hand to achieve compactness. The packed substrates within the bags were allowed to be pasteurised at $100{ }^{\circ} \mathrm{C}$ for the period of 12 hours (Jang et al., 2003). This was done using the Marshall Fowler electrode steamer. After pasteurisation the bagged substrates were allowed to cool at room temperature.

\subsection{Inoculation of substrate, spawn running and fruiting of mushroom}

The sterilised substrate was then inoculated at a rate of $2 \%$ of wet substrate with the previously prepared $P$. pulmonarius mushroom spawn. The Pleurotus pulmonarius mushroom was cultivated into four replicates for each selected level of the supplemented substrate. The substrates within the bags were inoculated strictly under aseptic conditions (laminar flow hood). The bags were inoculated by placing one spoonful of mother culture into the top surfaces of every bagged substrate. After inoculation, the substrates were closed tightly using rubber bands and cotton wool to prevent contamination but allows free gaseous exchange within the inoculated substrate. After inoculation the bags were incubated in a dark room at $25^{\circ} \mathrm{C}-27^{\circ} \mathrm{C}$ till the bags were fully colonised by the mushroom mycelia. The fully colonised bags were then transferred from the incubation room to the fruiting room that was constructed from plastic film supported by gum poles and covered by a double layer of $60 \%$ shade cloth. The inside of the fruiting room was fitted with micro-jet sprinklers that watered the mushrooms three times a day. After three fruiting flushes the experiment was terminated.

\subsection{Performance and productivity measurements}

The performance and productivity of the mushroom were measured using the method outlined by Mkhize et al. (2016). The following parameters were measured in order to evaluate the performance and productivity of $P$. pulmonarius mushroom. These included the biological efficiency, mycelial growth rate, number of contaminated bags, time to fruiting, yield of the mushroom and the number of days to full colonisation of substrate. The rate of mycelial advancement through the substrate was monitored in a six day interval by marking the areas where the mycelia 
growth ended. The markings were made at four equally spaced points around the bag using the measuring ruler. The days from the first colonisation of the substrate by the mycelia to the time when the mycelia fully covered the whole maize stalk substrate was noted and recorded. The bags which were fully colonised by mushroom mycelia were opened in the fruiting room, therefore the time taken by the mushroom to pin after full colonisation of the substrate was recorded and also the pin head formation after each and every flush was recorded for all the replicates. The yield of $P$. pulmonarius mushroom was calculated using the Equation 1 suggested by Morais et al. (2000), as follows:

$$
M Y=\left[\begin{array}{l}
\text { Weight of fresh mushroom harvested / } \\
\text { fresh substrate weight }
\end{array}\right]
$$

Thelast parameter which was the biological efficiency was calculated using the Equation 2 (Royse et al., 2004; Stamets, 2000), as follows:

$$
B E=\left[\begin{array}{l}
\text { weight of fresh mushroom harvested / } \\
\text { drysubstrate weight }
\end{array}\right] \times 100
$$

\subsection{The analysis of data and experimental arrangement}

The current experiments were arranged in a completely randomised design with four replications $(n=4)$. The data were analysed using SPSS version 23 and Microsoft Excel was used to construct the graphs. Tests used in the analysis, were Pearson's Correlation, Binomial Test for Proportions, and Repeated Measures ANOVA followed by post hoc Duncan's homogeneous groups. The $5 \%$ level of significance was used throughout.

\section{Results}

\subsection{Contamination}

From the observed results, there were no differences in the number of contaminated bags between the two supplements (wheat bran and maize flour). For each supplement, there were only three (9.4\%) contaminated bags out of 32 replicates (Table 1 ). Although there were no differences between (wheat bran) WB and (maize flour) MF in the number of contaminated bags, there were however differences in the number of contaminated bags within different levels of supplementation. It was observed that for WB supplement, the only level that experienced contamination was $20 \%$ WB (Table 1). This level of supplementation was heavily contaminated at $75 \%$ ( 3 out of 4 replicates). The levels of MF supplementation that experienced contamination were

Table 1. Effect of different supplement levels on the number of contaminated bags for the maize stalk substrate.

\begin{tabular}{ccc}
\hline Supplements & $\begin{array}{c}\text { Supplement Levels } \\
(\%)\end{array}$ & $\begin{array}{c}\text { Number of } \\
\text { contaminated bags. }\end{array}$ \\
\hline MF & 8 & 1 \\
& 12 & 1 \\
WB & 20 & 1 \\
& 20 & 3 \\
\hline
\end{tabular}

$8 \%, 12 \%$ and $20 \%$, which only experienced one contaminated bag $(25 \%)$ out of 4 replicates. This was an indication that MF did not increase the risk of contamination on P. pulmonarius when cultivated on maize stalk substrates. The current results indicated that $P$. pulmonarius was not highly affected by contamination except for the $20 \%$ WB supplement which experienced a high rate of contamination.

\subsection{The P. pulmonarius mushroom growth rate on the differently supplemented maize stalk substrate.}

The average mycelial growth rate (MGR) for the MF supplement treatment levels was not significantly different to the average MGR for WB supplement treatment levels $(p=0.96276$ ) (Figure 1). However, the MGR of $P$. pulmonarius was significantly $(p=0.00000)$ affected by various levels of both $\mathrm{WB}$ and $\mathrm{MF}$ supplements, which ranged from $0.28 \mathrm{~cm} /$ day to $0.74 \mathrm{~cm} /$ day (Table 2).

The highest MGR was observed at $2 \% \mathrm{MF}(0.74 \mathrm{~cm} /$ day $)$, $4 \% \mathrm{WB}(0.66 \mathrm{~cm} /$ day $)$ and $2 \% \mathrm{WB}(0.64 \mathrm{~cm} /$ day $)$ respectively (Table 2 ). The $2 \% \mathrm{MF}, 4 \% \mathrm{WB}$ and $2 \% \mathrm{WB}$ were significantly higher than the other levels of supplementation including the control ( $0 \%$ supplement). The mycelium growth rate gradually declined immediately after peaking at $2 \%$ and $4 \%$ for WB supplement (Figure 1). For the MF supplement the same pattern of mycelium growth was observed after peaking at $2 \%$.

\subsection{The number of days taken by P. pulmonarius to fully colonise the maize stalk base substrate}

The significant interaction waas observed between supplement material and different supplementation levels ( $p=0.00913$ ) on the number of days to full colonisation of maize stalk by $P$. pulmonarius mushroom. The results obtained indicated that the duration taken by $P$. pulmonarius to fully colonise the maize stalk substrate ranged from 30 to 69 days (Table 2). The shortest period to fully colonisation of substrate was observed at $2 \%$ for both WB and MF (30 days) followed by $4 \%$ WB (33 days) and $0 \%$ (control) with 39 days.

These minimum days to full colonisation that were observed for both WB and MF supplements were significantly shorter than the rest of the supplement levels. After reaching the minimum days at $2 \%$ for both $\mathrm{WB}$ and MF, then the days it took for $P$. pulmonarius to fully colonise maize stalk increased as the

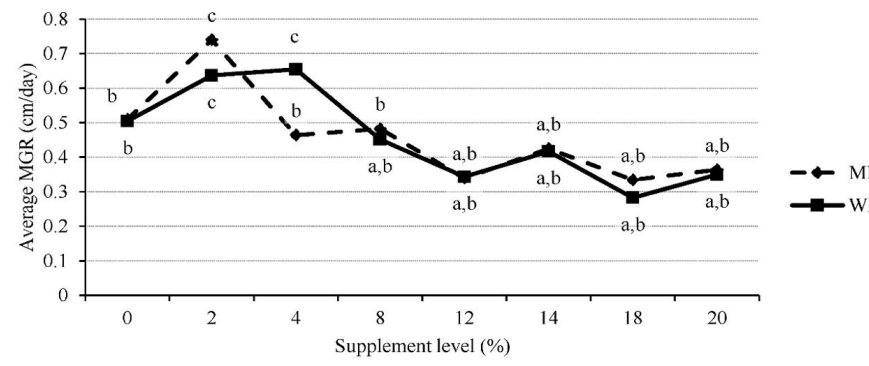

Figure 1. Mycelial growth rate of $P$. pulmonarius mushroom on each supplement level. Averages that have different letters are significantly different at $p<0.05$. 
Mkhize et al.

Table 2. Influence of various increasing levels of WB and MF supplements on the growth and productivity of P. pulmonarius mushroom grown on maize stalk.

\begin{tabular}{|c|c|c|c|c|c|}
\hline Supplements & Levels (\%) & MGR (cm/day) & Days & $\mathrm{BE}$ & MSY \\
\hline \multirow[t]{5}{*}{ MF } & 0 & $0.51 \pm 0.09^{\mathrm{b}}$ & $39 \pm 3^{a}$ & $67 \pm 5^{\mathrm{b}}$ & $0.07 \pm 0.00^{\mathrm{b}}$ \\
\hline & 2 & $0.74 \pm 0.04^{c}$ & $30 \pm 0^{\mathrm{a}}$ & $79 \pm 3^{\mathrm{b}}$ & $0.08 \pm 0.00^{\mathrm{bc}}$ \\
\hline & 4 & $0.47 \pm 0.04^{\mathrm{b}}$ & $53 \pm 4^{\mathrm{bc}}$ & $89 \pm 5^{b}$ & $0.09 \pm 0.01^{\mathrm{c}}$ \\
\hline & 12 & $0.34 \pm 0.02^{\mathrm{ab}}$ & $63 \pm 4^{\mathrm{d}}$ & $97 \pm 4^{\mathrm{b}}$ & $0.10 \pm 0.00^{c}$ \\
\hline & 14 & $0.42 \pm 0.02^{\mathrm{ab}}$ & $57 \pm 4^{c}$ & $132 \pm 9^{c}$ & $0.11 \pm 0.01^{c}$ \\
\hline \multirow[t]{5}{*}{ WB } & 0 & $0.50 \pm 0.09^{b}$ & $39 \pm 5^{\mathrm{a}}$ & $67 \pm 5^{b}$ & $0.07 \pm 0.00^{\mathrm{b}}$ \\
\hline & 2 & $0.64 \pm 0.01^{\mathrm{c}}$ & $30 \pm 0^{\mathrm{a}}$ & $80 \pm 2^{b}$ & $0.07 \pm 0.00^{\mathrm{b}}$ \\
\hline & 4 & $0.66 \pm 0.02^{\mathrm{c}}$ & $33 \pm 2^{\mathrm{a}}$ & $87 \pm 12^{\mathrm{b}}$ & $0.07 \pm 0.01^{b}$ \\
\hline & 8 & $0.45 \pm 0.06^{\mathrm{ab}}$ & $50 \pm 6^{\mathrm{bc}}$ & $101 \pm 9^{b c}$ & $0.08 \pm 0.01^{b c}$ \\
\hline & 12 & $0.34 \pm 0.02^{\mathrm{ab}}$ & $63 \pm 4^{\mathrm{d}}$ & $113 \pm 9^{c}$ & $0.09 \pm 0.01^{c}$ \\
\hline
\end{tabular}

The results are mean $\pm \mathrm{SE}$; $\mathrm{WB}=$ wheat bran; $\mathrm{MF}=$ maize flour; $\mathrm{BE}=$ Biological efficiency (a-c); MGR = mycelia growth rate ( $\mathrm{a}-\mathrm{c}$ ); MSY = Average mushroom yield (a-c); Days-number of days to full colonisation (a-d); Column with different letters indicate significant differences at $5 \%$.

supplement levels were increased further. Thus, the pattern of days to full colonisation of maize stalk showed that there was negative relationship between an increase in supplement level and duration to complete (full) colonisation of the substrate for WB and MF supplements at levels $>2 \%$ (Figure 2) of maize stalk for both WB and MF at levels $>2 \%$ (Figure 2).

\subsection{The effect of different levels of supplementation on the time for pinning of P. pulmonarius mushroom between the three flushes}

There was no significant interaction in the average time taken to pinning (TP) between the WB and MF supplements. The average TP at different levels of supplementation also showed no significant differences but the time for pinning of $P$. pulmonarius differed significantly between different flushes with the only overlaps occurring between flush 2 and flush 3 at $2 \% \mathrm{MF}, 14 \% \mathrm{MF}$ and $20 \% \mathrm{MF}$.

The TP ranged from 2 to 16 days (Table 3). The quicker pinning time was reported on the first flush from $4 \%$ to $20 \%$ (2 days) which was also statistically similar to other levels for the MF supplement. For the WB supplement, $12 \%$ and $18 \%$ (2 days) showed the shortest pinning time which was also statistically similar to other or rest WB supplement levels. The longest pinning time was recorded on the third flush at the $20 \%$ WB (16 days) which was statistically similar to other levels of supplementation on flush 3 with the only exception on $2 \%$ and $14 \%$ MFs. The results in Table 3 shows that the $P$. pulmonarius was exceptionally quicker in initiation of pin heads. Overall the results observed indicated that there was no significant differences between supplement levels for both WB and MF, however there were differences between the flushes since the first flush had the shortest time for pinning.
Table 3. Influence of WB and MF supplement on the time required by the mycelia to initiate pinning between flushes.

\begin{tabular}{ccccc}
\hline Supplements & Levels (\%) & Flush 1 TP & Flush 2 TP & Flush 3 TP \\
\hline MF & 0 & $4 \pm 0^{\mathrm{a}}$ & $10 \pm 1^{\mathrm{b}}$ & $14 \pm 3^{\mathrm{c}}$ \\
& 2 & $3 \pm 0^{\mathrm{a}}$ & $9 \pm 1^{\mathrm{b}}$ & $12 \pm 2^{\mathrm{b}}$ \\
& 4 & $2 \pm 0^{\mathrm{a}}$ & $10 \pm 1^{\mathrm{b}}$ & $13 \pm 1^{\mathrm{c}}$ \\
& 8 & $2 \pm 0^{\mathrm{a}}$ & $10 \pm 1^{\mathrm{b}}$ & $12 \pm 2^{\mathrm{c}}$ \\
& 12 & $2 \pm 0^{\mathrm{a}}$ & $8 \pm 2^{\mathrm{b}}$ & $14 \pm 1^{\mathrm{c}}$ \\
& 14 & $2 \pm 0^{\mathrm{a}}$ & $10 \pm 2^{\mathrm{b}}$ & $11 \pm 2^{\mathrm{b}}$ \\
WB & 18 & $2 \pm 0^{\mathrm{a}}$ & $8 \pm 1^{\mathrm{b}}$ & $12 \pm 1^{\mathrm{c}}$ \\
& 20 & $2 \pm 0^{\mathrm{a}}$ & $13 \pm 0^{\mathrm{c}}$ & $13 \pm 1^{\mathrm{c}}$ \\
& 0 & $4 \pm 0^{\mathrm{a}}$ & $10 \pm 1^{\mathrm{b}}$ & $14 \pm 3^{\mathrm{c}}$ \\
& 2 & $4 \pm 0^{\mathrm{a}}$ & $8 \pm 0^{\mathrm{b}}$ & $15 \pm 3^{\mathrm{c}}$ \\
& 4 & $3 \pm 0^{\mathrm{a}}$ & $9 \pm 0^{\mathrm{b}}$ & $12 \pm 3^{\mathrm{c}}$ \\
& 8 & $3 \pm 0^{\mathrm{a}}$ & $9 \pm 1^{\mathrm{b}}$ & $15 \pm 3^{\mathrm{c}}$ \\
& 12 & $2 \pm 0^{\mathrm{a}}$ & $9 \pm 2^{\mathrm{b}}$ & $14 \pm 3^{\mathrm{c}}$ \\
& 14 & $3 \pm 0^{\mathrm{a}}$ & $11 \pm 1^{\mathrm{b}}$ & $13 \pm 0^{\mathrm{c}}$ \\
& 18 & $2 \pm 0^{\mathrm{a}}$ & $7 \pm 2^{\mathrm{b}}$ & $12 \pm 1^{\mathrm{c}}$ \\
& 20 & $3 \pm 0^{\mathrm{a}}$ & $7 \pm 3^{\mathrm{b}}$ & $16 \pm 3^{\mathrm{c}}$ \\
\hline
\end{tabular}

Averages with different letters in each column are significantly different at $p \leq 0.05$.

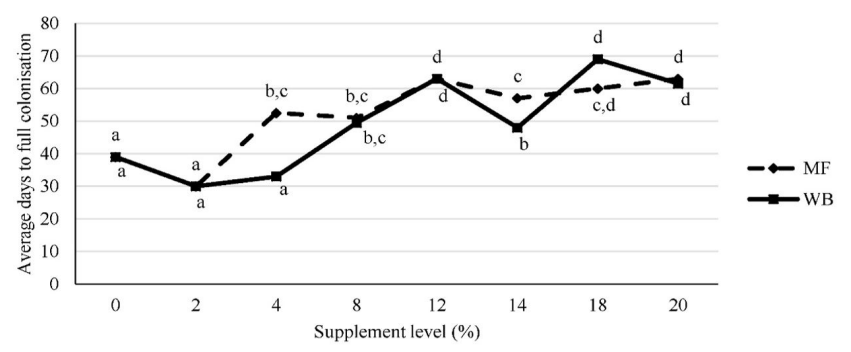

Figure 2. Average number of days taken by the mushroom to fully colonise the substrate supplemented with varying levels of WB and MF supplements. Averages that have different letters are significantly different at $p<0.05$. 


\subsection{The evaluation of biological efficiency $(\mathrm{BE})$ of $P$. pulmonarius mushroom grown on maize stalk substrate supplemented with various levels of WB and MF supplements}

The results for biological efficiency (BE) indicates that significant interaction exist between supplement level and the supplement type $(p=0.01411)$. The differences between the two supplement materials in BE were small at low supplement levels, but increased at higher supplement levels $\geq 14 \%$ (Figure 3).

It was noted that for the MF supplement, $\mathrm{BE}$ increased from $67 \pm 5$ at $0 \%$ to $132 \pm 9$ at $14 \% \mathrm{MF}$ and thereafter decreased to $73 \pm 24$ at $20 \% \mathrm{MF}$ (Figure 3). For WB the BE increased from $67 \pm 5$ at $0 \%$ to $113 \pm 9$ at $12 \%$ after which it decreased to $32 \pm 24$ at $20 \%$ (Figure 3 ). The BE for WB decreased more than that for MF at supplement treatment levels $\geq 14 \%$.

\subsection{Yield of P. pulmonarius mushroom grown on substrate supplemented with various levels of maize flour and wheat bran supplements}

The results obtained indicated that there was no significant interaction that existed between the supplement type and supplement level ( $p=0.16642$ ). However the average yield of MF supplement was significantly higher than the average yield of WB supplement $(p=0.00124)$. The yield response pattern to increasing level of supplementation indicates a gradual yield increase with increasing supplement level to peak at $14 \%$ for MF and $12 \%$ for $\mathrm{WB}$ ) after which it eventually declined. The decrease was greater for WB than it was for MF (Figure 4).

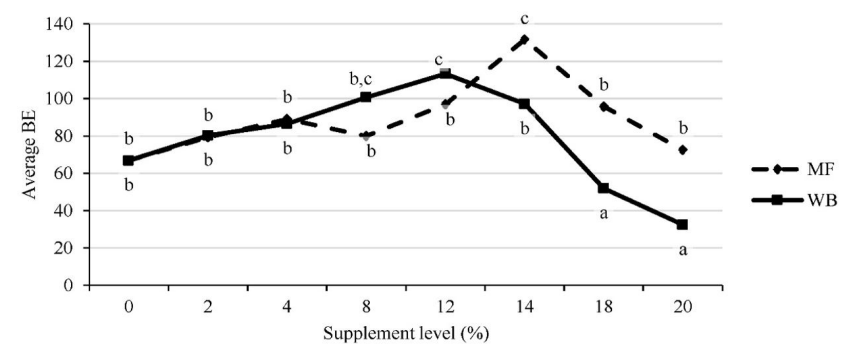

Figure 3. Biological efficiency of $P$. pulmonarius mushroom grown on substrate supplemented with different levels of WB and MF supplement. Averages that have different letters are significantly different at $p<0.05$.

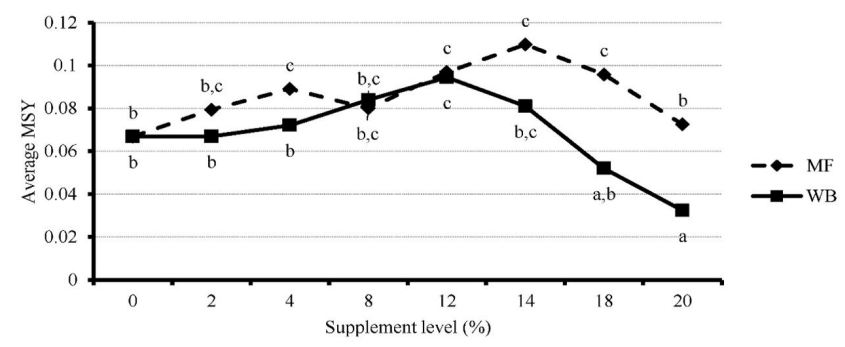

Figure 4. Average yield of Pleurotus pulmonarius on substrate supplemented with various increasing levels of wheat bran and maize flour supplement. Averages that have different letters are significantly different at $p<0.05$.

\section{Discussion}

The cultivation of mushrooms requires the growing material or the substrate which have enough carbohydrates and nitrogen in order to facilitate fast growth of the mushroom (Oei, 1996; Ayodele \& Okhuoya, 2007). However, the major obstacle in mushroom cultivation is that the contamination can also occur with an increased nutrient concentration of the substrate (Wabali \& Wocha, 2013). The incidence of contamination such as fungal contamination within the substrate has a huge negative impact on the growth and yield of mushroom because the fungal contaminants compete with the cultivated mushroom (Tisdale, 2004). Therefore, finding ways of improving yield and production of mushroom has become the major objective of mushroom research (Soko et al., 2008). In the current research, the rate of substrate contamination was not highly influenced by the increase in the concentration of the supplements in both the WB and MF supplement. The level that showed exception in the number of contaminated bags was $20 \%$ WB since it experienced high rate of contamination of 3 bags (75\%) out of 4 replicates. This indicated that the $P$. pulmonarius was highly susceptible to contamination when the $20 \%$ WB was mixed with maize stalk. The low level of contamination observed at $8 \%, 12 \%$ and $20 \% \mathrm{MF}$ was probably due to partial break down of the substrate (Balasubramanya \& Kathe, 1996). The high level of contamination on the $20 \% \mathrm{WB}$ may be due to the fact that the substrate at this level of WB supplementation became too rich in nitrogen, which promoted the growth of competitor organisms (Oei, 2003) which proved the findings by Wabali \& Wocha (2013) who stated that higher nutrient concentration promoted the growth of competitor fungi. Furthermore it is known that the addition of supplements into the mushroom growing substrate causes some changes in the decomposition rate of the substrate by the mushroom (Ayodele \& Okhuoya, 2007). This was evidenced in the current study, since different levels of supplements had remarkably different rate of mycelium growth which were significantly different to the control and other levels. As observed that the lowest levels of supplementation such as $2 \%$ MF, 4\% WB and 2\% WB had significantly higher mycelial growth rate (MGR) which showed similarities to the results which were reported by Gume et al. (2013) who obtained mycelial extension of $0.69 \mathrm{~cm} /$ day on $\mathrm{sdZcCh}$ (combination of Cordia Africana and Pouteria adolfi-friederici sawdust, corncobs and coffee bean husks), $0.64 \mathrm{~cm} /$ day on $\mathrm{ZcCh}$ (corncobs and coffee bean husks) and $0.60 \mathrm{~cm} /$ day on $\mathrm{sd}^{1} \mathrm{ch}$ (combination of $C$. Africana sawdust and coffee bean husks) and $\mathrm{sd}^{2} \mathrm{ch}$ ( $P$. adolfi-friederici sawdust and coffee bean husks). The higher levels of supplementation showed significant lower MGR especially from $8 \%$ to $20 \%$ for both WB and MF. There was a gradual decline in MGR as the level of supplementation was increased (Figure 1). This was probably caused by high levels of nitrogen which the substrate experienced as the levels of supplementation increased. Therefore these results are in agreement with Maziero (1990) who stated that high nitrogen concentration results in reduced degradation of lignin by mushrooms. High MGR and short duration of substrate colonisation could be useful in mushroom cultivation, since the shorter colonisation period minimises the growth of flies and contaminants within substrate, resulting in quicker return of investment (Kopytowski \& Minhoni, 2004). The results from the 
current study indicated that higher supplementation rate causes an increased or delay in period of mushroom growth whereas lower levels of supplementation showed shorter colonisation period (Table 2). The delay caused by higher supplementation was possibly caused by excessive nitrogen, which usually limits the growth of the mushroom when it is in abundance within the substrate (Yang et al., 2013). The delayed growth of $P$. pulmonarius resulted in the maize stalk being more prone to fungal and bacterial infections (Philippoussis et al., 2001; Diamantopoulou et al., 2006). There is therefore need to balance the supplement with nitrogen to avoid long duration before full colonization and contaminations without compromising on yield. The observed results of the shortest time to full colonisation of substrate corresponded to the results stipulated by (Liang et al., 2011) who obtained $30.9 \pm 0.9$ days for P. pulmonarius. The time for pinning (TP) was significantly different between different flushes. The time it took for P. pulmonarius to initiate pin heads was significantly faster for flush 1 compared to flush 2 and flush 3 respectively (Table 3 ). This indicated that the time for pinning of $P$. pulmonarius is affected by an increase in the number of flushes and this might be due to the availability of free circulating carbohydrates within the substrate (Chang, 2006). The earliness in pinning on the first flush clearly showed that the first flush contained high levels of nutrients which are believed to influence the mycelia to be vigorous in growth, and therefore calls for early pinning (Onyango et al., 2011). The early or fast time for pinning observed in the current study concur with (Dahmardeh et al., 2010) who reported TP of 2 - 3 days. Parameters such as yield and biological efficiency are important parameters to be taken into consideration for success in mushroom cultivation. As the biological efficiency parameter indicates the ability of the mushroom to fruit on the substrate (Fan et al., 2000). The obtained results indicated that the addition of both WB and MF supplement onto the maize stalk substrate greatly influenced the production of $P$. pulmonarius as the values of $\mathrm{BE}$ ranged from $67 \%$ (control) to $132 \%$ (Table 2 ). The biological efficiency gradually increased with increasing level of supplement for both WB and MF and there is a point where $\mathrm{BE}$ reached the peak or maximum and thereafter significantly dropping into lowest form. The decrease in biological efficiency after achieving peak in both WB and MF supplement could be due to an increase in supplementation which tends to generate heat which end up overheating the substrate and influence growth of mushroom leading to unsatisfactory or poor yield (Assan \& Mpofu, 2014). Over all the results of $\mathrm{BE}$ indicates that $P$. pulmonarius was successfully cultivated on the maize stalk substrate with exception on the $20 \% \mathrm{WB}$ which showed low BE of $32 \%$ due to contamination. The biological efficiency of the control ( $0 \%$ supplement) corresponds to the findings of Assan \& Mpofu (2014) who reported the BE of $(66.88 \pm 4.59)$. The mushroom yield is another important parameter in mushroom production which is influenced by different factors such as environmental conditions and substrate supplementation with different additives (Mane et al., 2007). The recorded results of the $P$. pulmonarius mushroom indicate that the increase in the level of supplementation result in the increased mushroom yield. These findings support the research of Moonmoon et al. (2011), Patil et al. (2011), Raymond et al. (2013) who reported that the yield showed a trend of increasing with an increase in level of supplementation and at some point it decreases. The lower yield of $P$. pulmonarius on higher levels of WB and MF (Table 2) was probably due to heat generated by higher supplement level (Assan \& Mpofu, 2014) and also excess nitrogen within substrate with high levels of supplements which is known to have an influence on yield and growth of mushroom (Déo \& Faustin, 2015). The 14\% for maize flour supplement and $12 \%$ for wheat bran gave the highest mushroom yield which shows that at this level, there was appropriate levels of nutrients.

\section{Conclusion}

The outcome of the study indicates that the addition of supplement (WB and MF) has great influence in the performance of $P$. pulmonarius on the maize stalk substrates. The contamination was not highly experienced in most of the levels of supplements, exception for high levels of supplementation such as the $20 \%$ WB which indicated to be highly affected by contamination. The different levels of MF and WB influenced the production period and production rate of $P$. pulmonarius. This is because high levels of supplementation tend to slow the growth rate and increase the period to full colonisation of maize stalk and vice versa. Although high levels of supplementation delays the production period, they are however advantageous in obtaining better production (yield and BE) as observed that increasing level of supplement resulted in increasing yield and BE but up to a certain point where production turns to drop. Based on the outcome of the current work, it may be recommended that for fast production low levels of supplements can be used. For higher yield or production the $14 \% \mathrm{MF}$ and $12 \% \mathrm{WB}$ is recommended and beyond these values the production decreases.

\section{References}

Alarcón, J., \& Águila, S. (2006). Lovastatin production by Pleurotus ostreatus: effects of the C: $\mathrm{N}$ ratio. Zeitschrift für Naturforschung C, 61(1-2), 95-98. PMid:16610224. http://dx.doi.org/10.1515/znc2006-1-217.

Assan, N., \& Mpofu, T. (2014). The influence of substrate on mushroom productivity. Scientific Journal of Crop Science, 3(7), 86-91.

Ayodele, S., \& Okhuoya, J. (2007). Effect of substrate supplementation with wheat bran, NPK and urea on Psathyrella atroumbonata Pegler sporophore yield. African Journal of Biotechnology, 6(12), 1414-1417.

Balasubramanya, R., \& Kathe, A. (1996). An inexpensive pretreatment of cellulosic materials for growing edible oyster mushrooms. Bioresource Technology, 57(3), 303-305. http://dx.doi.org/10.1016/ S0960-8524(96)00086-7.

Bano, Z., \& Srivastava, H. (1962). Studies on the cultivation of Pleurotus spp. on paddy straw. Food Sci., 12, 363-365.

Chang, S. T. (1991). Biological and commercial aspects of straw mushroom cultivation. Mushroom Science, 9(2), 157-165.

Chang, S. T. (2006). The world mushroom industry: trends and technological development. International Journal of Medicinal Mushrooms, 8(4), 297-314. http://dx.doi.org/10.1615/IntJMedMushr.v8.i4.10.

Chang, S., \& Miles, P. (1982). Introduction to mushroom science. In S. T. Chang \& T. H. Quimio (Eds.), Tropical mushrooms: biological nature and cultivation methods (pp. 3-10). Hong Kong: Chinese University Press. 
Chang, S., Lau, O., \& Cho, K. (1981). The cultivation and nutritional value of Pleurotus sajor-caju. European Journal of Applied Microbiology and Biotechnology, 12(1), 58-62. http://dx.doi.org/10.1007/BF00508120.

Chang-Ho, Y., \& Yee, N. (1977). Comparative study of the physiology of Volvariella volvacea and Coprinus cinereus. Transactions of the British Mycological Society, 68(2), 167-172. http://dx.doi.org/10.1016/ S0007-1536(77)80004-1.

Croan, S. C. (2000). Conversion of wood waste into value-added products by edible and medicinal Pleurotus (Fr.) P. Karst. species (Agaricales sl, Basidiomycetes). International Journal of Medicinal Mushrooms, 2(1), 73-80. http://dx.doi.org/10.1615/IntJMedMushr.v2.i1.80.

Dahmardeh, M., Hossienabadi, R., \& Safarpoor, H. (2010). Comparative study on cultivation and yield performance of Pleurotus ostreatus (oyster mushroom) grown on different substrates (wheat straw and barley straw) and supplemented at various levels of spawn. Journal of Food Agriculture and Environment, 8(3-4 Part 2), 996-998.

Déo, N., \& Faustin, K. (2015). Effect of substrates and doses of urea on growth and yield of an oyster mushroom (Pleurotus ostreatus) in greenhouse. International Journal of Agricultural Policy and Research, 3(8), 314-322.

Diamantopoulou, P., Philippoussis, A., Kastanias, M., Flouri, F., \& Chrysayi-Tokousbalides, M. (2006). Effect of famoxadone, tebuconazole and trifloxystrobin on Agaricus bisporus productivity and quality. Scientia Horticulturae, 109(2), 190-195. http://dx.doi. org/10.1016/j.scienta.2006.04.008.

Dzomeku, M. (2009). Studies on the Occurrence, Ethnomycology and Cultivation of Pleurotus Tuber-Regium (PhD Dissertation). Kwame Nkrumah University of Science and Technology, Kumasi.

Fan, L., Pandey, A., Mohan, R., \& Soccol, C. (2000). Use of various coffee industry residues for the cultivation of Pleurotus ostreatus in solid state fermentation. Acta Biotechnologica, 20(1), 41-52. http:// dx.doi.org/10.1002/abio.370200108.

Fritsche, G. (1978). Breeding work. In S. Chang \& W. Hayes (Eds.), The Biology and Cultivation of Edible Mushrooms (pp. 239-248). New York: Academic Press.

Gume, B., Muleta, D., \& Abate, D. (2013). Evaluation of locally available substrates for cultivation of oyster mushroom (Pleurotus ostreatus) in Jimma, Ethiopia. African Journal of Microbiological Research, 7(20), 2228-2237. http://dx.doi.org/10.5897/AJMR12.895.

Gunde-Cimerman, N., \& Cimerman, A. (1995). Pleurotus fruiting bodies contain the inhibitor of 3-hydroxy-3-methylglutaryl-coenzymeA reductase lovastatin. Experimental Mycology, 19(1), 1-6. PMid:7614366. http://dx.doi.org/10.1006/emyc.1995.1001.

Hussein, J. M., Tibuhwa, D., Mshandete, A., \& Kivaisi, A. K. (2015). Antioxidant properties of seven wild edible mushrooms from Tanzania. African Journal of Food Science, 9(9), 471-479. http:// dx.doi.org/10.5897/AJFS2015.1328.

Jang, K. Y., Jhune, C. S., Park, J. S., Cho, S. M., Weon, H. Y., Cheong, J. C., \& Sung, J. M. (2003). Characterization of fruitbody morphology on various environmental conditions in Pleurotus ostreatus. Mycobiology, 31(3), 145-150. http://dx.doi.org/10.4489/MYCO.2003.31.3.145.

Jedinak, A., \& Sliva, D. (2008). Pleurotus ostreatus inhibits proliferation of human breast and colon cancer cells through p53-dependent as well as p53-independent pathway. International Journal of Oncology, 33(6), 1307-1313. PMid:19020765.

Kopytowski, J. Fo, \& Minhoni, M. (2004). Nitrogen sources and C/N ratio on yield of Agaricus blazei. The International Society for Mushroom Science, 16(1), 213-220.

Kwon, H. (2004). Cultivation modes. In Mushworld (Org.), Mushroom growers Handbook 1 (chap. 7, pp. 167-171). Haiku: Aloha Medicinals.
Lavi, I., Levinson, D., Peri, I., Tekoah, Y., Hadar, Y., \& Schwartz, B. (2010). Chemical characterization, antiproliferative and antiadhesive properties of polysaccharides extracted from Pleurotus pulmonarius mycelium and fruiting bodies. Applied Microbiology and Biotechnology, 85(6), 1977-1990. PMid:19830415. http://dx.doi.org/10.1007/ s00253-009-2296-X.

Liang, Z. C., Wu, K. J., Wang, J. C., Lin, C. H., \& Wu, C. Y. (2011). Cultivation of the culinary-medicinal lung oyster mushroom, Pleurotus pulmonarius (Fr.) Quél.(Agaricomycetideae) on grass plants in Taiwan. International Journal of Medicinal Mushrooms, 13(2), 193-199. PMid:22135896. http://dx.doi.org/10.1615/IntJMedMushr. v13.i2.120.

Mane, V. P., Patil, S. S., Syed, A. A., \& Baig, M. M. V. (2007). Bioconversion of low quality lignocellulosic agricultural waste into edible protein by Pleurotus sajor-caju (Fr.) Singer. Journal of Zhejiang University. Science. B., 8(10), 745-751. PMid:17910118. http://dx.doi.org/10.1631/ jzus.2007.B0745.

Masarirambi, M. T., Mamba, M. B., \& Earnshaw, D. M. (2011). Effects of Various Substrates on Growth and Yield of Oyster Mushroom (Pleurotus ostreatus). Asian. The Journal of Agricultural Science, 3(4), 275-280.

Maziero, R. (1990). Substratos alternativos para o cultivo de Pleurotus spp (Dissertação de Mestrado). Instituto de Biociências, Universidade São Paulo, São Paulo.

Mkhize, S. S., Cloete, J., Basson, A. K., \& Zharare, G. E. (2016). Performance of Pleurotus ostreatus mushroom grown on maize stalk residues supplemented with various levels of maize flour and wheat bran. Food Science and Technology, 36(4), 598-605. http:// dx.doi.org/10.1590/1678-457x.08516.

Moonmoon, M., Shelly, N. J., Khan, M. A., Uddin, M. N., Hossain, K., Tania, M., \& Ahmed, S. (2011). Effects of different levels of wheat bran, rice bran and maize powder supplementation with saw dust on the production of shiitake mushroom (Lentinus edodes (Berk.) Singer). Saudi Journal of Biological Sciences, 18(4), 323-328. PMid:23961143. http://dx.doi.org/10.1016/j.sjbs.2010.12.008.

Morais, M., Ramos, A., Matos, N., \& Oliveira, E. J. S. (2000). Note. Production of shiitake mushroom (Lentinus edodes) on lignocellulosic residues/Nota. Cultivo del hongo shiitake (Lentinus edodes) en residuos lignocelulósicos. Food Science \& Technology International, 6(2), 123-128. http://dx.doi.org/10.1177/108201320000600206.

Munoz, C., Guillen, F., Martinez, A., \& Martinez, M. (1997). Induction and characterization of laccase in the ligninolytic fungus Pleurotus eryngii. Current Microbiology, 34(1), 1-5. PMid:8939793. http:// dx.doi.org/10.1007/s002849900134.

Obodai, M., Cleland-Okine, J., \& Vowotor, K. (2003). Comparative study on the growth and yield of Pleurotus ostreatus mushroom on different lignocellulosic by-products. Journal of Industrial Microbiology \& Biotechnology, 30(3), 146-149. PMid:12715251. http://dx.doi.org/10.1007/s10295-002-0021-1.

Oei, P. (1996). Mushroom cultivation. Leiden: Technical Centre for Agricultural and Rural Co-operation.

Oei, P. (2003). Mushroom cultivation: appropriate technology for mushroom growers. The Netherlands: Backhuys Publishers.

Onyango, B., Palapala, V., Arama, P., Wagai, S., \& Otieno, C. (2011). Nutritional analysis of some composted and non-composted agricultural substrates used for production of Kenyan native Wood Ear Mushrooms [Auricularia auricular (L. Ex Hook.) Underw.]. Am. Journal of Food Technology, 10(6), 804-816.

Patil, K. K., Kulkarni, R. V., \& Gupta, D. N. (2011). Enhancing yield and Biological Efficiency (BE) in Oyster Mushroom by supplementation. Academic Journal Plant Sciences, 4(2), 41-44. 
Philippoussis, A., Zervakis, G., \& Diamantopoulou, P. (2001). Bioconversion of agricultural lignocellulosic wastes through the cultivation of the edible mushrooms Agrocybe aegerita, Volvariella volvacea and Pleurotus spp. World Journal of Microbiology \& Biotechnology, 17(2), 191-200. http://dx.doi.org/10.1023/A:1016685530312.

Pramanik, M., Mondal, S., Chakraborty, I., Rout, D., \& Islam, S. S. (2005). Structural investigation of a polysaccharide (Fr. II) isolated from the aqueous extract of an edible mushroom, Pleurotus sajor-caju. Carbohydrate Research, 340(4), 629-636. PMid:15721333. http:// dx.doi.org/10.1016/j.carres.2004.12.032.

Raymond, P., Mshandete, A. M., \& Kivaisi, A. K. (2013). Cultivation of oyster mushroom (Pleurotus HK-37) on solid sisal waste fractions supplemented with cow dung manure. JBLS, 4(1), 273-286.

Royse, D. J. (2002). Influence of spawn rate and commercial delayed release nutrient levels on Pleurotus cornucopiae (oyster mushroom) yield, size, and time to production. Applied Microbiology and Biotechnology, 58(4), 527-531. PMid:11954801. http://dx.doi. org/10.1007/s00253-001-0915-2.

Royse, D. J., Rhodes, T., Ohga, S., \& Sanchez, J. (2004). Yield, mushroom size and time to production of Pleurotus cornucopiae (oyster mushroom) grown on switch grass substrate spawned and supplemented at various rates. Bioresource Technology, 91(1), 85-91. PMid:14585625. http://dx.doi.org/10.1016/S0960-8524(03)00151-2.

Smiderle, F. R., Olsen, L. M., Carbonero, E. R., Baggio, C. H., Freitas, C. S., Marcon, R., Santos, A. R. S., Gorin, P. A. J., \& Iacomini, M. (2008). Anti-inflammatory and analgesic properties in a rodent model of a $(1 \rightarrow 3),(1 \rightarrow 6)$-linked $\beta$-glucan isolated from Pleurotus pulmonarius. European Journal of Pharmacology, 597(1), 86-91. PMid:18789924. http://dx.doi.org/10.1016/j.ejphar.2008.08.028.
Soko, M., Madula, M., Mankhwanda, T., Langisi, Z., Banda, A., \& Theu, M. (2008, September 14-20). Evaluations of different possible Pleurotus spp. planting spawn media for use in the spawn industry. In M. P. K. J. Theu (Ed.), Plant protection progress report for the 2007/2008 season presented at the Department of Agricultural Research Services Planning and Review Meeting (pp. 32-40). Mangochi, Malawi: Ministry of Agriculture and Food Security.

Stamets, P. (2000). Growing gourmet and medicinal mushrooms (vol. 3). California: Ten Speed Press Berkeley.

Tisdale, T. E. (2004). Cultivation of the oyster mushroom (Pleurotus sp.) on wood substrates in Hawaii (M.S.c. Thesis). University of Hawaii, Honolulu.

Wabali, C. V., \& Wocha, I. (2013). The effect of nutrient concentration on the yield of mushroom (Pleurotus Osttreatus). Greener Journal of Agricultural Sciences, 3(6), 437-444.

Wahab, N. A. A., Abdullah, N., \& Aminudin, N. (2014). Characterisation of potential antidiabetic-related proteins from Pleurotus pulmonarius (Fr.) Quél.(grey oyster mushroom) by MALDI-TOF/TOF mass spectrometry. BioMed Research International, 2014, 131607. PMid:25243114. http://dx.doi.org/10.1155/2014/131607.

Yang, W., Guo, F., \& Wan, Z. (2013). Yield and size of oyster mushroom grown on rice/wheat straw basal substrate supplemented with cotton seed hull. Saudi Journal of Biological Sciences, 20(4), 333338. PMid:24235869. http://dx.doi.org/10.1016/j.sjbs.2013.02.006.

Zhang, J. (2005, December 8-22). Composting and nutrients. In Seminar on edible fungi application and dissemination for officials from developing countries (pp. 31). Beijing, China. 